\title{
NÍVEL DE GOVERNANÇA DAS EMPRESAS ESTATAIS CONTROLADAS PELO ESTADO DO CEARÁ À LUZ DA LEI 13.303/2016 E DECRETOS ESTADUAIS REGULAMENTADORES
}

\author{
LEVEL OF GOVERNANCE OF STATE-OWNED ENTERPRISES \\ CONTROLLED BY CEARÁ STATE IN LIGHT OF THE LAW \\ 13.303/2016 AND ITS STATE'S REGULATORY DECREES
}

\author{
NIVEL DE GOBERNANZA DE LAS EMPRESAS ESTATALES \\ CONTROLADAS POR EL ESTADO DEL CEARÁ A LA LUZ DE \\ LA LEY 13.303/2016 Y SUS REGULACIONES ESTATALES
}

Alana Pinto de Macedo da Silva

Analista de Controle Externo do Tribunal de

Contas do Ceará, Brasil

Pós-graduanda em Gestão Pública - Universidade

de Fortaleza, Brasil

alanapmsilva@gmail.com

Paulo Roberto de Carvalho Nunes

Docente da Universidade de Fortaleza, Brasil

Doutor em Administração de Empresas -

Universidade de Fortaleza, Brasil

prnunes@unifor.br
Contextus

ISSNe 2178-9258

Organização: Comitê Científico Interinstitucional Editor-Chefe: Diego de Queiroz Machado Avaliação: double blind review pelo SEER/OJS

Recebido em 23/07/2019

Aceito em 11/11/2019

Versão final aceita em 26/11/2019

http://dx.doi.org/10.19094/contextus.v17i3.41664

\section{RESUMO}

O estudo objetiva diagnosticar o nível de governança das empresas públicas e sociedades de economia mista controladas pelo Estado do Ceará, baseando-se nas regras de governança previstas na Lei 13.303/2016 e respectivos decretos estaduais regulamentadores. Para mensurar o nível de governança, foi utilizado o indicador de governança IG-SEST. Os resultados indicam progresso, em relação à implementação dos mecanismos de governança e conformidade normativa, pela maioria das estatais que participaram da pesquisa, com $78 \%$ delas enquadradas nos níveis 1 e 2 (nota > 5,09). No entanto, uma minoria pouco avançou nesse sentido. O desempenho mais baixo foi percebido nos itens que compõem a dimensão transparência das informações, indicando que a $66,66 \%$ das empresas estão pouco ou nada aderentes às regras. Esses resultados são relevantes principalmente para a prática dos gestores públicos interessados em adotar estratégias para se adequar à nova lei.

Palavras-chave: governança; governança pública; lei 13.303/2016; empresas estatais; Ceará.

\begin{abstract}
The purpose of this study is to diagnose the level of governance of state-owned enterprises controlled by the State of Ceará, based on the governance rules established in Law 13.303/2016 and its state regulations. The IG-SEST governance indicator was used to measure the level of governance. The results indicate progress on legal compliance. Most of the participating stated-owned enterprises (78\%) were classified in levels 1 and 2 (grade > $5,09)$. However, a small part of the enterprises has made little progress in this regard. The worst performance was perceived in the items that integrate the transparency of information dimension, indicating that $66.66 \%$ of enterprises are not adherent enough or at all to the rules. These results are relevant mainly for the practice of public managers interested in adopting strategies to conform to the new law.
\end{abstract}

Keywords: governance; public governance; law 13.303/2016; state-owned enterprises; Ceará.

\section{RESUMEN}

El estudio tiene como objetivo diagnosticar el nivel de gobernanza de las empresas estatales controladas por el Estado de Ceará, según las reglas de gobernanza del Ley 13.303/2016 y sus regulaciones estatales. El indicador de gobernanza IG-SEST se utilizó para medir el nivel de gobernanza. Los resultados indican avances en el 
cumplimiento legal. La mayoría de las empresas estatales participantes (78\%) se clasificaron en los niveles 1 y 2 (nota $>5,09$ ). Sin embargo, una minoría ha avanzado poco en este sentido. El peor desempeño se percibió en los ítems de la dimensión transparencia de la información, indicando que el 66,66\% de las empresas adhieren poco o nada a las reglas. Estos resultados son relevantes principalmente para la práctica de los gerentes públicos interesados en adoptar estrategias para cumplir con la nueva ley.

Palabras clave: gobernanza; gobernanza publica; ley 13.303/2016; empresas estatales; Ceará.

\section{INTRODUÇÃO}

A governança corporativa é concebida como instrumento que impulsiona as organizações, contribuindo para maximizar geração de valor e eficiência, por meio de aprimoramento da gestão, administração e responsabilidade das empresas (FERREIRA et al., 2019). Num contexto público, a governança está intrinsecamente correlacionada aos conceitos de democracia, accountability e transparência, no intuito de assegurar a boa gestão dos recursos públicos (OLIVEIRA; TAZINASSO, 2015).

Oliveira e Tazinasso (2015) comparam as sete maiores economias mundiais, no período entre 2009 e 2013, e assinalam baixo grau de desempenho do Brasil, notadamente no que concerne à eficácia governamental. $\mathrm{O}$ estudo se baseou nos resultados dos Indicadores de Governança Mundial - WGI, que avaliam seis dimensões da governança: voz e responsabilidade; estabilidade política e ausência de violência/terrorismo; eficácia governamental; qualidade regulatória/normativa; Estado/Regime de Direito; controle da corrupção.

As empresas estatais brasileiras são grandes influenciadoras dos sistemas sociais, econômicos e políticos do país, com potencial de geração de empregos, receitas, apoio a setores da economia etc., constituindo meio de participação estatal na ordem econômica (FONTES FILHO, 2018). Tamanho potencial, contudo, viu-se ameaçado por práticas de atos de corrupção e falta de controles e de ética no âmbito da Administração Pública, sobressaltadas após caso emblemático envolvendo estatal de grande porte vir a público (MAXIMIANO, 2017; PINHO, 2017; SILVA, J., 2018), cenário oportuno para o surgimento da Lei 13.303/2016.

Assim, passados dezoito anos da edição da Emenda à Constituição 19/1998, a Lei 13.303/2016 vem regulamentar o artigo 173, $§ 1^{\circ}$, da Constituição Federal de 1988, inserindo a obrigatoriedade de adoção, por todas as empresas públicas e sociedades de economia mista brasileiras, de normas relacionadas à governança corporativa, transparência e controle, além de regras mais flexíveis atinentes a licitações e contratações (ZYMLER, 2017). E, para que as empresas se adaptassem às mudanças, foi instituído prazo legal de 24 meses, encerrado em 30/06/2018, a partir de quando a lei passou a ser exigível de todas as estatais brasileiras. 
O Governo do Estado do Ceará, atualmente, possui controle acionário, seja direto ou indireto, em onze empresas estatais, duas constituídas sob a forma de empresa pública, e nove constituídas sob a forma de sociedade de economia mista (CEARÁ, 2019). No Estado, a Lei 13.303/2016 foi regulamentada pelos Decretos 32.112/2016 e 32.243/2017, aplicável às estatais de menor e maior receita operacional, respectivamente.

Com base nesse cenário, a pertinência da temática proposta parte dos desafios que foram impostos às estatais para se adequarem à nova ordem jurídica no interregno de dois anos e, ao mesmo tempo, da urgente necessidade de implementação de medidas de governança a fim de contribuir para mitigar riscos de práticas corruptivas e melhorar a eficiência na gestão dessas entidades governamentais.

Para direcionar a análise, formulou-se a seguinte questão de pesquisa: qual o nível de governança das empresas estatais sob controle acionário do Estado do Ceará à luz das regras de governança instituídas na Lei 13.303/2016 e nos decretos estaduais regulamentadores? Logo, o objetivo deste trabalho é diagnosticar o nível de governança das empresas públicas e sociedades de economia mista controladas pelo Estado do Ceará, baseando-se nas regras de governança previstas na Lei 13.303/2016 e respectivos decretos estaduais regulamentadores.

Nesse intuito, será calculado indicador de governança, reproduzindo o indicador IGSEST, metodologia desenvolvida e aplicada pela Secretaria de Coordenação e Governança das Empresas Estatais - SEST, órgão que integra a administração direta da União. Os resultados serão relevantes para gestores públicos que tenham interesse em avaliar a conformidade da entidade à nova lei, possibilitando comparação entre as estatais e servindo de benchmarking para promover o aprimoramento da gestão e a implementação dos mecanismos de governança, assim como para órgãos de controle, subsidiando estratégias de fiscalização e orientação.

Além da introdução, a estrutura do trabalho abrange as seções: referencial teórico, dividida em três tópicos principais: governança corporativa; governança no setor público; e Lei 13.303/2016 e Decretos Estaduais regulamentadores; metodologia, explicando método de cálculo e conceitos envolvendo o indicador de governança IG-SEST; resultados e discussão, apresentando conclusões da análise dos dados coletados na pesquisa; e conclusão, expondo considerações, pontos de discussão e sugestões para futuros objetos de pesquisa. 


\section{REFERENCIAL TEÓRICO}

\subsection{Governança Corporativa}

A governança corporativa surge como medida reativa a problemas afetos à teoria da agência, a qual "busca analisar relações em que a propriedade e o controle são designados a pessoas distintas" (ALTOUNIAN; SOUSA; LAPA, 2017, p. 250), decorrência da pulverização do capital acionário das empresas. Modela-se, assim, um controle empresarial composto por principais/outorgantes (acionistas) e agentes/outorgados (gestores), em que estes cuidam de decisões voltadas a negócio, estratégia, gestão e operação, enquanto aqueles focam em decisões financeiras e de alocação eficaz de recursos (ROSSETTI; ANDRADE, 2019).

Nessa relação acionista-gestor espera-se a maximização do valor da organização e da riqueza pelo primeiro, como contrapartida da remuneração ofertada ao segundo (ROSSETTI; ANDRADE, 2019). Contudo, cada parte operará na maximização de sua utilidade, situação em que o interesse do agente (gestor) não necessariamente é compartilhado com o do principal (acionista) (JENSEN; MECKLING, 1976), podendo ocorrer divergências nas decisões, e, como consequência, o conflito de agência (NUNES, 2016; ROSSETTI; ANDRADE, 2019).

Diante desses conflitos e como forma de contenção ou mitigação do problema é gerado o que se denomina custos de agência (NUNES, 2016), que inclui despesas com: criação e estruturação de contratos entre o principal e o agente, monitoramento das atividades dos gestores, perdas residuais advindas de divergências de decisões e demonstração da não prejudicialidade de seus atos pelos gestores (SILVA, E., 2016).

Portanto, a governança lança-se como solução para conciliar as ações dos gestores com os objetivos dos acionistas. Ela vem superar o conflito e o custo de agência (SILVA, E., 2016) e proporcionar credibilidade às empresas, gerenciando riscos e resultados, o que eleva o valor da organização e o interesse de investidores (ALTOUNIAN; SOUSA; LAPA, 2017).

A Organização para Cooperação e Desenvolvimento Econômico - OCDE percebe a governança como instrumento de desenvolvimento sustentável (econômico, ambiental e social) para o crescimento econômico mundial (ALTOUNIAN; SOUSA; LAPA, 2017). Nessa lógica, a governança também pode ser conceituada como aquisição e distribuição de poder na sociedade, e, em um contexto corporativo, passa a ser compreendida como o modo pelo qual são administradas as organizações (MATIAS-PEREIRA, 2010).

No cenário internacional, uma das inspirações sobre o tema governança é o Cadbury Report, publicado em 1992, contemplando, segundo Nunes (2016, p. 46), “código de melhores 
práticas, papel, composição e responsabilidades do conselho de administração, auditoria e relação com as partes interessadas”.

De outra parte, ainda na década de 1990, a OECD (1999, p. 10, tradução nossa) assentou que:

A governança corporativa envolve um conjunto de relacionamentos entre administradores, conselheiros, acionistas e outras partes interessadas. Governança corporativa também fornece a estrutura para estabelecer os objetivos da empresa e determinar os meios para atingi-los e monitorar seu desempenho.

No Brasil, o Instituto Brasileiro de Governança Corporativa - IBCG, fundado em 1995, é referência no assunto, e, a partir de 1999, começou a editar a publicação Código das Melhores Práticas sobre Governança Corporativa (MATIAS-PEREIRA, 2010), com última versão atualizada em 2015, no qual apresenta a seguinte definição:

Governança corporativa é o sistema pelo qual as empresas e demais organizações são dirigidas, monitoradas e incentivadas, envolvendo os relacionamentos entre sócios, conselho de administração, diretoria, órgãos de fiscalização e controle e demais partes interessadas. (IBCG, 2015, p. 20).

Na ocasião, o IBCG (2015) também apresenta como princípios básicos da governança corporativa: transparência, equidade, prestação de contas/accountability e responsabilidade corporativa. A transparência se correlaciona à qualidade da comunicação (interna e externa) e propicia um clima de confiança nas relações, podendo ser concretizada pela divulgação e acesso às boas práticas, tais como: relatório anual de administração, políticas e diretrizes de governança, política de transações com partes relacionadas, política de divulgação de informações relevantes, política de dividendos, acordo de acionistas, código de ética e conduta, estatuto social bem definido, demonstrativos financeiros, dentre outros (SILVA, E., 2016).

A equidade busca promover isonomia no tratamento dos grupos minoritários, a exemplo da política de transações com as partes relacionadas, devendo garantir liberdade de expressão, de acesso à informação, de associação, de voto, dentre outras (MARTINS, 2018; SILVA, E., 2016). Já a prestação de contas/accountability abrange o dever de prestação de contas dos agentes eleitos e a responsabilização por seus atos, observada em assembleia de acionistas, planejamento estratégico e plano de negócios, divulgação de indicadores de desempenho empresarial, demonstrações financeiras, relatório de administração e outros (SILVA, E., 2016).

Por fim, a responsabilidade corporativa está atrelada à função social das organizações e à sua perenidade, exigindo que na definição dos negócios e operações sejam considerados impactos sociais e ambientais, podendo se materializar na política de responsabilidade corporativa e compliance e na demonstração do valor adicionado (SILVA, E., 2016). 
A despeito da diversidade de concepções e da abrangência dada à governança corporativa na literatura, há convergências nos conceitos, princípios, finalidades e práticas (SILVA, E., 2016). Vê-se, assim, que as abordagens conceituais de governança corporativa seguem essencialmente quatro linhas principais: guardiã de direitos, sistema de relações, estrutura de poder e sistema normativo (ROSSETTI; ANDRADE, 2019).

Sintetizando esse leque conceitual, Rossetti e Andrade (2019, p. 117) propõem a seguinte definição para governança corporativa: “conjunto de princípios, propósitos, processos e práticas que rege o sistema de poder e os mecanismos de gestão das empresas", que, dentre outras coisas, envolvem: propósitos dos proprietários, relações proprietários-conselho-direção, maximização do retorno dos proprietários, minimização dos conflitos, controle e fiscalização dos gestores, sistema de informações relevantes e prestação de contas às partes interessadas.

A governança, portanto, orienta-se para solucionar o problema de agência e busca conciliar interesses (FONTES FILHO, 2018) com o objetivo de agregar valor ao negócio e ampliar a captação de recursos e investimentos, contribuindo para a qualidade da gestão e perenidade das organizações (IBGC, 2015).

\subsection{Governança no setor público}

Fazendo uma releitura da teoria da agência para o meio governamental, a relação de agência é formada em um lado pelos contribuintes, no lugar do principal/acionista, quem capitaliza e espera do governo o máximo retorno e dividendos sociais (bens e serviços de interesse público), e na outra ponta tem-se os agentes/gestores públicos, com interesses de garantir e elevar benefícios próprios, configurando o conflito (ROSSETTI; ANDRADE, 2019).

Assim, a complexidade do Estado, com múltiplos atores envolvidos (governo, legislativo, conselheiros, dirigentes, proprietários etc.) no sistema de responsabilidades, onde sequer há identificação clara de beneficiários, propicia conflitos que podem gerar decisões ineficientes, que não atendem ao interesse do principal (OCDE, 2015). Inclusive, agregando essa cadeia de responsabilidades aos diversos interesses que permeiam os objetivos das empresas estatais, forma-se ambiente propício para surgimento da disfunção denominada por Koppell (2005) de multiple accountability disorder, decorrente da tentativa de atender expectativas conflitantes de diversas partes interessadas (FONTES FILHO, 2018).

Como visto, a governança trilhou seus primeiros passos no mundo corporativo privado, contudo, crises vivenciadas pelo Estado criaram ambiente propício para alargamento de seus 
institutos também à seara estatal (BRASIL, 2015). Tanto que o Banco Mundial, no final da década de 1980, diante do que denominou problemas de má governança, elaborou agenda de reforma para as administrações de Estados nacionais na América do Sul, Ásia e África, considerando que a ausência da boa governança nessas instâncias interferia no nível de desempenho que é exigido em seus programas de empréstimos (MATIAS-PEREIRA, 2010).

Um dos primeiros trabalhos sobre governança governamental foi desenvolvido pela Federação Internacional de Contadores - IFAC, em meados de 2001, quando lançou o estudo 13 - Governança no Setor Público, adaptando princípios e recomendações da governança corporativa à realidade pública, como forma de contribuir para a melhoria da credibilidade e da gestão das organizações (ALTOUNIAN; SOUZA; LAPA, 2017; BRASIL, 2015).

Posteriormente, em 2013, a IFAC e o Instituto Revisor de Finanças e Contabilidade Pública - CIPFA, elaboraram conjuntamente a publicação "Framework Internacional: Boa Governança no Setor Público", onde foram instituídos princípios e estruturas para implementar a boa governança, aplicáveis a entidades de todos os tamanhos, com o objetivo de incentivar melhorias na prestação de serviços públicos e de estabelecer um referencial para a governança no setor público (IFAC, 2013). Segundo a IFAC (2013, p. 8, tradução nossa), governança “compreende os arranjos colocados em prática para garantir que os resultados pretendidos pelas partes interessadas sejam definidos e alcançados".

A IFAC (2013) define como princípios da boa governança no setor público: forte compromisso com a integridade, os valores éticos e as leis; transparência e engajamento das partes interessadas; definir resultados em termos de benefícios econômicos, sociais e ambientais sustentáveis; determinar intervenções necessárias para otimizar o alcance dos resultados pretendidos; desenvolver a capacidade da entidade, incluindo a capacidade de sua liderança e de cada indivíduo que a integra; gerenciar riscos e desempenho por meio de um controle interno robusto e forte e de uma gestão forte das finanças públicas; implementar boas práticas em transparência e relatórios para uma prestação de contas eficaz.

Ainda no âmbito global, a OCDE desenvolveu um estudo, publicado inicialmente em 2005 e atualizado em 2015, que resultou em recomendações para operação eficiente, transparente e responsável das empresas estatais, com base em padrões internacionais sobre a função da propriedade estatal, objetivando profissionalizar o Estado como proprietário, propiciar eficiência, transparência e responsabilidade no funcionamento das estatais e assegurar competitividade com equidade entre estatais e empresas privadas (OCDE, 2015).

O estudo contempla diretrizes e recomendações para as seguintes áreas: razões para a propriedade estatal; papel do Estado como proprietário; atuação das estatais no mercado; 
tratamento equitativo dos acionistas e outros investidores; relações com partes interessadas e responsabilidade empresarial; divulgação de informações e transparência; responsabilidade da alta administração; e complementam os princípios do G20/OCDE, quais sejam:

I) Assegurar a base para um enquadramento efetivo do governo das sociedades; II) Os direitos e o tratamento paritário dos acionistas e as funções principais da propriedade; III) Investidores institucionais, mercados de ações e outros intermediários; IV) O papel dos stakeholders; V) Divulgação de informação e transparência; e VI) As responsabilidades do conselho. (OCDE, 2016, p. 12).

No Brasil, além do Código das Melhores Práticas de Governança Corporativa, do IBGC, também aplicável a empresas estatais, outra obra notável é o Referencial Básico de Governança Aplicável a Órgãos e Entidades da Administração Pública, elaborado pelo Tribunal de Contas da União - TCU. Alinhado aos objetivos da IFAC, a Corte de Contas Federal apresenta a seguinte definição para governança no setor público: “compreende essencialmente os mecanismos de liderança, estratégia e controle postos em prática para avaliar, direcionar e monitorar a atuação da gestão, com vistas à condução de políticas públicas e à prestação de serviços de interesse da sociedade" (TCU, 2014, p. 26).

Para o TCU (2014), a governança no setor público pode ser observada sob diferentes perspectivas e tem como princípios: legitimidade (atendimento ao interesse público e bem comum); equidade (garantia de condições às partes interessadas para acesso e exercício de seus direitos); responsabilidade (sustentabilidade das organizações); eficiência (equilíbrio entre a qualidade do serviço e do gasto); probidade (zelo pela coisa pública), transparência (acessibilidade às informações relevantes) e accountability (prestação responsável de contas).

Portanto, a compreensão de governança abrange conceitos e objetivos comuns aos ambientes públicos e privados, ambos buscando solucionar questões relacionadas ao conflito de agência (NUNES, 2016), definição de objetivos, atribuição de poder e responsabilidades, e monitoramento da gestão (MATIAS-PEREIRA, 2010).

No entanto, um fator que diferencia a governança das empresas privadas e estatais é que os propósitos destas são ampliados, pois, além de atender às estruturas e obrigações do contexto privado (jurídica, acionistas, conselho de administração, normas contábeis, divulgação das informações, valor empresarial, estrutura econômica e financeira etc.), precisam cumprir os objetivos das políticas públicas nas quais se inserem (NUNES, 2016; OCDE, 2015).

No âmbito acadêmico, Nunes (2016) ressalta que poucos são os estudos empíricos que relacionam práticas de governança a variáveis institucionais, societária ou de desempenho em empresas estatais. A despeito dessa limitação, identificou-se o estudo de Faria e Streit (2016), que busca identificar, analisar e comparar os aspectos principais da governança em bancos 
centrais, revelando, dentre outros pontos, que definir papéis e responsabilidades, estabelecer regras de composição e funcionamento de comitês, avaliar o desempenho, dar transparência aos atos e decisões e instituir instâncias de governança são essenciais para a boa governança e credibilidade dessas organizações.

Silva, F. (2018), amparado também na teoria da agência, se propôs a buscar evidências da melhoria no desempenho das empresas estatais após a implantação da Lei 13.303/2016 com as práticas de governança, concluindo que não é possível confirmar melhora nos resultados das estatais. Na ocasião, associa esse resultado, dentre outros fatores, à morosidade no setor público, ao longo prazo para implementação da lei e a outras leis já existentes que abordam o tema.

Fortini e Shermam (2017), por sua vez, ao examinarem de que modo o controle interno da Administração Pública brasileira pode ser aprimorado por meio da incorporação de mecanismos e procedimentos de governança, destacam que leis recentes, a exemplo da Lei das Estatais, visam implementar mecanismos de aperfeiçoamento da gestão pública, favorecendo a integridade, no entanto, tais medidas precisam ser efetivamente fomentadas e implementadas para que produzam seus resultados.

Outra base comumente aplicada na administração pública para construção de mecanismos de governança é a teoria institucional. Para essa teoria as pressões institucionais do ambiente sobre as entidades moldam o comportamento dos atores (MATIAS-PEREIRA, 2010), a partir dos processos de reprodução: mimético, compartilhamento de concepções (cultural-cognitivo); normativo, padrões comportamentais da vida social; e coercitivo, definição de regras, monitoramento e sanção. O agir, portanto, tem como justificativas: desconhecimento de outro caminho, obrigação moral ou evitar punição (SCOTT, 2008).

Sustentados nessa teoria, alguns trabalhos ressaltam a maior influência da pressão coercitiva sobre a divulgação e adoção de práticas e mecanismos de governança corporativa, a qual deriva de medidas cogentes (legislações), cujo descumprimento pode resultar em sanções (OLIVEIRA et al., 2017; OLIVEIRA; CEGLIA; ANTÔNIO FILHO, 2016; LIMA et al., 2015).

A relevância desse tema foi ainda ressaltada em levantamento realizado pelo Tribunal de Contas da União em 2014, em atuação conjunta com outros Tribunais de Contas e associações, que teve por objetivo "sistematizar informações sobre a situação da governança pública em âmbito nacional”, contando com a participação de mais de 7.000 mil órgãos e entidades públicas (ALTOUNIAN; SOUZA; LAPA, 2017; BRASIL, 2015, p. 1).

Como resultado, foi apresentado o panorama nacional e federal da governança pública e o Índice de Governança Pública - IGG, retratando, em suma, que a maioria das organizações públicas nacionais ainda estão em estágio inicial no que se relacionada à capacidade nos 
mecanismos de governança (ALTOUNIAN; SOUZA; LAPA, 2017). Ademais, num recorte por esfera, a situação mais alarmante se encontra nos Estados e Municípios, notadamente os das regiões Norte e Nordeste, indicando deficiências de atuação nas instâncias internas de governo para alcance de bom desempenho na gestão pública (BRASIL, 2015; NARDES, 2018).

A despeito do desafio posto com relação à governança pública no Brasil, vale ressaltar que aspectos históricos, econômicos, institucionais, sociais e culturais do país influenciam na estrutura de governança (FARIA; STREIT, 2016). Assim, na transposição dos modelos corporativos privados para o meio público deve-se reconhecer as características próprias das organizações, como estrutura, tamanho, cultura etc. (ALTOUNIAN; SOUZA; LAPA, 2017).

E nesse sentido, as diretrizes da OCDE (2015) para as estatais, além de indicar recomendações internacionais na implementação da governança, busca a resolução de problemas próprios dessas entidades, respeitando suas características. Portanto, espera-se que os caminhos encontrados para adoção dos mecanismos de governança no contexto público mostrem iniciativas de "criatividade, inovação em gestão pública e organização do interesse político" (FONTES FILHO; PICOLIN, 2008, p. 1186).

\subsection{Lei 13.303/2016 e Decretos Estaduais regulamentadores}

\subsubsection{Abrangência e aplicabilidade}

A Lei 13.303/2016, rotulada como Lei das Estatais ou Lei de Responsabilidade das Estatais (SILVA, F., 2018), regula duas temáticas principais: governança e compras públicas (ZYMLER, 2017), com aplicabilidade às empresas públicas e sociedades de economia mista, independentemente da esfera do ente (União, Estado, Distrito Federal e Município), ou do tipo (empresa estatal, estatal dependente, subsidiária, sociedade de propósito específico, consórcio etc.) (ANTUNES, 2017; FERRAZ, 2018). Aliás, nota-se equalização legal até quanto à natureza da atividade desempenhada, já que a lei não opera distinção de abrangência às estatais que exploram atividade econômica e às que prestam serviços públicos (BICALHO, 2017).

A exceção de aplicação integral das regras se deu apenas às estatais de receita operacional inferior a $\mathrm{R} \$ 90$ milhões, e se o ente controlador editar regulamentação própria para essas empresas até 31/12/2016. Por ocasião da sua edição, a norma instituiu prazo de 24 meses (art. 91), encerrado em 30/06/2018, para que as empresas a ela se ajustassem, considerando 
principalmente regras que impunham a adoção de mudanças administrativas dos processos, estruturas, regulamentos e a necessidade de alterações estatutárias (ANTUNES, 2017).

No Estado do Ceará, a flexibilização de alguns dispositivos da Lei 13.303/2016 para as empresas de menor porte ocorreu por meio da edição do Decreto Estadual 32.112/2016, de 23/12/2016, alterado posteriormente mediante Decreto Estadual 32.722/2018, de 25/06/2018. Além desses, foi editado o Decreto Estadual 32.243/2017, de 31/05/2017, que reafirma a necessidade de adequação das empresas de grande porte integralmente às novas regras de governança da Lei de Responsabilidade das Estatais.

\subsubsection{Mecanismos de governança}

A Lei 13.303/2016 desenvolve o tema governança com enfoque em 3 aspectos principais: transparência, fiscalização e controle, e administração (IBGC, 2017). O objetivo é "aprimorar a governança corporativa das estatais [...] buscando gestão mais profissional e técnica em detrimento das políticas, ampliando transparência das informações das empresas e tentando reduzir a intervenção política nas estruturas” (SILVA, F., 2018, p. 32).

Observa-se já no artigo $6^{\circ}$ da norma a instituição de conteúdo mínimo a ser previsto no estatuto social das estatais: regras de governança corporativa, de transparência, e de estruturação e práticas de gestão de riscos e de controle interno, assim pensado, possivelmente, por causa da contínua interação entre essas temáticas ao longo da norma (FERRAZ, 2018).

A partir dessa perspectiva, vê-se que as regras de governança corporativa, que objetivam a atuação ética e maximização dos resultados, podem ser encontradas no artigo $8^{\circ}$, incisos I, II, III e VIII: carta anual explicitando compromissos de consecução de objetivos de políticas públicas, recursos a serem empregados e impactos-financeiros para alcance dos objetivos; adaptação dos estatutos sociais à lei de criação da estatal; divulgação de informações relevantes; divulgação da carta anual de governança consolidando informações relativas a atividades desenvolvidas, estrutura de controle, fatores de risco, dados econômico-financeiros, políticas de governança corporativa, remuneração da administração e outras (FERRAZ, 2018).

Com efeito, no artigo $8^{\circ}$ verifica-se comunicação das temáticas acima introduzidas. No entanto, sua essência é o tema transparência, compreendida, de acordo com Ferraz (2018, p. 5), na concepção ampla da publicidade, tanto sob a forma ativa, "divulgação ampla e geral de atos e fatos da vida empresarial”, como passiva, "acesso do público às informações relativas a tais atos e fatos eventualmente não divulgados amplamente e em caráter geral”. 
Aliás, verifica-se o intento de: combater o uso de informação privilegiada, instituindo regime de divulgação de informação da CVM (art. $8^{\circ}, \S 3^{\circ}$ ), e ampliar a transparência, disponibilizando de forma permanente e cumulativa ( $\operatorname{art} .8^{\circ}, \S^{\circ}$ ) documentos e informações (FERRAZ, 2018). Dentre esses últimos destacam-se: as políticas (art. $8^{\circ}$, inc. IV, V e VII), o relatório integrado ou de sustentabilidade (art. $8^{\circ}$, inc. IX), e a remuneração dos administradores (art. $8^{\circ}$, inc. III; e art. 12, inc. I), práticas estas perfiladas às recomendações da OCDE (2015) que tratam de relação com stakeholders e negócios responsáveis e de abertura e transparência (SILVA, J., 2018).

A área responsável pela gestão de riscos e verificação do cumprimento de obrigações, previstos no artigo $9^{\circ}$, possui caráter preventivo e busca mitigar a possibilidade de prejuízos, sejam decorrentes de atos ilegais ou inerentes à própria atividade empresarial, e propiciar a adequada responsabilização dos agentes. No texto legal observa-se diversos instrumentos nesse sentido: estrutura de governança comprometida com metas para realização de seus fins sociais e das políticas públicas (art. $8^{\circ}$, inc. I); controle interno regular e contínuo (art. $9^{\circ}$, inc. I); poderes da área de verificação do cumprimento de obrigações de reportar irregularidades diretamente ao conselho de administração (art. $9^{\circ}$, inc. II e $\S 4^{\circ}$ ) (FERRAZ, 2018).

Em complemento, a auditoria interna também integra a estrutura de controle, prevista no artigo $9^{\circ}$, inciso III e $\S 3^{\circ}$, instância vinculada à alta gestão, imbuída de aferir a efetividade da gestão de riscos e a adequação dos controles internos, cuidando de cada etapa do processo de formação das demonstrações financeiras e zelando pela governança. A propósito, há ainda previsão de comitê de auditoria estatutário (arts. $9^{\circ}$, inc. III, e 24), órgão auxiliar do conselho de administração, encarregado de promover o controle por meio da supervisão, monitoramento e avaliação das atividades desempenhadas pelas áreas de controle interno e auditoria interna (FERRAZ, 2018).

Também no artigo $9^{\circ}, \S^{\circ}$ e incisos, há previsão para elaboração e divulgação de código de conduta e integridade, orientado a combater corrupção, fraude e conflitos de interesses, dispondo sobre canal de denúncias, mecanismos de proteção ao denunciante, sanções e treinamentos sobre os preceitos do código, regras também aderentes à recomendação relações com partes interessadas e responsabilidade empresarial da OCDE (2015) (SILVA, J., 2018).

Outra novidade foi o dever de adoção de "práticas de governança e controle proporcionais à relevância, à materialidade e aos riscos do negócio do qual são participantes" até mesmo em empresas privadas em que a estatal não detenha o controle acionário, participação minoritária, como estabelecido no $§ 7^{\circ}$, do artigo $1^{\circ}$ (MAXIMIANO, 2017, p. 222). 
A gestão de riscos e o controle são percebidos ainda na instituição de requisitos e impedimentos à indicação de dirigentes e membros dos conselhos e comitês (arts. 16, 17, 25 e 26) e de requisitos específicos para exercício dos cargos de diretores (art. 13, inc. II), regras que profissionalizam a gestão e garantem independência para tomada de decisão. E, para assegurar o cumprimento dos requisitos e impedimentos legais pelos diretores e membros indicados, foi criado o comitê estatutário de elegibilidade (art. 10). Também nesse sentido e inspirados na Comissão de Valores Mobiliários - CVM e no IBGC, a lei previu a participação de membros independentes nos conselhos e comitês (arts. 22 e 25) (LUPION, 2018).

A profissionalização da gestão ainda é priorizada na previsão de treinamentos aos administradores $\left(\operatorname{art.~17,~} 4^{\circ}\right.$ ) sobre temas como: atividades empresariais, legislações aplicáveis (societária, mercado de capitais e anticorrupção), código de conduta, controle interno e outros, consonante com a recomendação da OCDE (2015) que trata das responsabilidades dos colegiados de administração das estatais (SILVA, J., 2018).

Na esteira dessa acepção, também a assunção de compromissos com metas e resultados pelos diretores (art. 23) e a fiscalização e divulgação do atendimento das metas e resultados na execução do plano de negócios e estratégia (art. 23, $\S \S 2^{\circ}$ e $3^{\circ}$ ) elevam "padrão de profissionalismo e de visão de longo prazo" do administrador (CAMARGO, 2017, p. 174).

No âmbito do Estado do Ceará, o Decreto Estadual 32.112/2016 vem regulamentar a Lei 13.303/2016 para as estatais cearenses de menor porte, flexibilizando as normas de governança. Nos seus dispositivos observa-se: ausência de previsão de auditoria interna, do comitê estatutário de auditoria e do comitê de elegibilidade; elaboração facultativa do código de conduta e integridade; ausência de previsão de participação de membros independentes no conselho de administração.

Não obstante, a Lei 13.303/2016, artigo $1^{\circ}, \S 1^{\circ}$, cita dispositivos aplicáveis de imediato até mesmo às empresas de pequeno porte, os artigos $2^{\circ}, 3^{\circ}, 4^{\circ}, 5^{\circ}, 7^{\circ}, 8^{\circ}, 11,12$ e 27 , que tratam essencialmente de definições, vinculação da participação minoritária ao objeto social da investidora, aplicação das regras da Lei 6.404/1976 e da CVM, transparência e divulgação, debêntures e partes beneficiárias, código de conduta e integridade, arbitragem, divulgação da remuneração dos administradores e função social (ANTUNES, 2017).

Sem a pretensão de exaurir todos os artigos da lei e regulamentos, interessa notar que práticas e mecanismos tratados na norma, como algumas regras atinentes à transparência e à divulgação de informações, accountability e integridade, já eram impostas às estatais em decorrência de legislações preexistentes, como é o caso das Lei de Acesso à Informação 
(12.527/2011), da Lei Anticorrupção (12.846/2013) e da Lei de Conflitos de Interesses (12.813/2013) (FORTINI; SHERMAM, 2017).

Como inovações de fato trazidas pela lei, em relação aos mecanismos de governança, citam-se a estruturação dos conselhos de administração e fiscal, da auditoria interna, e dos comitês estatutários de auditoria e de elegibilidade (MARTINS, 2018; SILVA, F., 2018), o regime de nomeação dos dirigentes (FONTES FILHO, 2018) e a elaboração de carta anual com os compromissos de consecução dos objetivos de políticas públicas (MARTINS, 2018).

\section{METODOLOGIA}

Para responder à questão de pesquisa: “qual o nível de governança das empresas estatais sob controle acionário do Estado do Ceará à luz das regras de governança instituídas na Lei 13.303/2016 e nos decretos estaduais regulamentadores? ”, foi aplicado questionário, composto de 33 itens de avaliação, em nove empresas estatais. O questionário foi elaborado com base no indicador de governança IG-SEST, ferramenta desenvolvida e aplicada pela Secretaria de Coordenação e Governança das Empresas Estatais - SEST, no âmbito das empresas estatais federais, na forma de ciclos de avaliação, com resultados dos três primeiros ciclos divulgados, conforme quadro 1, e já disponível na web regulamento do quarto ciclo (SEST, 2019).

Quadro 1 - Ciclos de Avaliação do IG-SEST no âmbito das estatais federais

\begin{tabular}{|l|l|}
\hline Ciclo de avaliação & Data das certificações IG-SEST \\
\hline Primeiro & Novembro/2017 \\
\hline Segundo & Maio/2018 \\
\hline Terceiro & Novembro/2018 \\
\hline
\end{tabular}

Fonte: elaboração própria com base em dados de Brasil (2019).

O IG-SEST consiste em um instrumento de acompanhamento que se propõe a avaliar o desempenho da governança e da internalização da Lei 13.303/2016 no âmbito das estatais federais, colaborando para processo de conformidade legal e incentivando a implementação de boas práticas de governança. Como resultado é obtida uma performance estática do nível de governança da entidade (RIBEIRO NETO et al., 2018).

Em síntese, o IG-SEST é concebido em 3 camadas. A primeira constitui agrupamentos temáticos de maior amplitude, as dimensões. A segunda, os blocos, refere-se ao desdobramento das dimensões, com delimitação dos temas. E a terceira, os itens de avaliação, é o detalhamento dos blocos, extraídos dos dispositivos das normas e regulamentos. Ademais, foram atribuídos 
pesos às camadas dimensão, bloco e itens de avaliação, com base na graduação dos critérios relevância, acurácia e complexidade de execução, respectivamente (SEST, 2017).

A relevância modera o destaque dado à dimensão naquele ciclo de avaliação, considerada sua importância na governança das estatais. Já a acurácia precisa a estrutura de gestão implantada na entidade, por meio da ponderação dos blocos. Enfim, a complexidade de execução leva em conta a dificuldade das ações para implementar os requisitos legais, mediante sopesamento dos itens de avaliação. Os três critérios são graduados, e, então, são atribuídos pesos, como se visualiza no quadro 2 (SEST, 2017). Ressalta-se que não foi identificada, no regulamento do IG-SEST, a razão dos diferentes valores dos pesos das graduações das camadas.

Quadro 2 - Camadas, graduações e ponderações do IG-SEST

\begin{tabular}{|l|l|l|}
\hline Camada & Grau de relevância & Peso \\
\hline \multirow{4}{*}{ Dimensão } & Alto & 4 \\
\cline { 2 - 3 } & Médio & 3 \\
\cline { 2 - 3 } & Baixo & 2 \\
\hline \multirow{3}{*}{ Camada } & Grau de acurácia & Peso \\
\hline Camada & Alto & 3 \\
\cline { 2 - 3 } & Médio & 2 \\
\cline { 2 - 3 } & Baixo & 1 \\
\hline \multirow{3}{*}{ Item de avaliação } & Grau de complexidade & Peso \\
\hline & Alto & 5 \\
\cline { 2 - 3 } & Médio & 3 \\
\cline { 2 - 3 } & Baixo & 1 \\
\hline
\end{tabular}

Fonte: elaboração própria com base na SEST (2017).

Ao final é gerada uma planilha em Excel ${ }^{\circledR}$ com os itens de avaliação, os quais poderão receber uma das seguintes respostas: (i) "Sim", correspondente à nota 1 (um), quando o item for evidenciado; (ii) "Não", correspondente à nota 0 (zero), caso o item não seja evidenciado; (iii) "N/A", quando o item não for, por algum motivo justificado, aplicável à empresa, hipótese que não interferirá na pontuação. No âmbito da SEST, as respostas aos itens de avaliação são submetidas à análise e validação do Comitê de Avaliação, criado especificamente para esse fim.

Diante da avaliação, é calculado o indicador de governança, com base nas equações:

Índice Bloco $=\frac{\sum(\text { Item de Avaliação x Peso Item de Avaliação })}{\sum \text { Peso Item de Avaliação }}$

Índice Dimensão $=\frac{\sum(\text { Bloco x Peso Bloco })}{\sum \text { Peso Bloco }}(2)$

Indicador de Governança $=\frac{\sum(\text { Dimensão x Peso Dimensão })}{\sum \text { Peso Dimensão }}$ 
O indicador de governança é então multiplicado por 10, gerando uma nota que varia de 0 a 10, agrupada de forma a possibilitar classificação em quatro níveis, sendo o nível 1 representativo da melhor avaliação, consoante quadro 3 a seguir:

Quadro 3 - Níveis de governança

\begin{tabular}{|l|l|}
\hline Nota & Nível de governança \\
\hline 7,60 a 10,00 & Nível 1 \\
\hline 5,10 a 7,59 & Nível 2 \\
\hline 2,60 a 5,09 & Nível 3 \\
\hline 0,00 a 2,59 & Nível 4 \\
\hline
\end{tabular}

Fonte: SEST (2017).

Além disso, há ainda a possibilidade de aferir o grau de criticidade dos itens não atendidos na avaliação, por meio do produto do peso do item de avaliação com os pesos do bloco e da dimensão em que se insere, escalonando da forma mostrada no quadro 4.

Quadro 4 - Grau de criticidade dos itens não atendidos

\begin{tabular}{|l|l|}
\hline Produto & Grau de criticidade \\
\hline 2 a 10 & Baixa \\
\hline 10 a 40 & Média \\
\hline 40 a 60 & Alta \\
\hline
\end{tabular}

Fonte: elaboração própria com base na SEST (2017).

A presente pesquisa foi baseada no regulamento do primeiro ciclo de avaliação do IGSEST, que aplicou 45 itens de avaliação, distribuídos em 3 dimensões e 11 blocos, e deu enfoque à conformidade legal, entendida como mais apropriada para uma abordagem inicial às estatais. Referido regulamento foi obtido mediante solicitação via sistema eletrônico do serviço de informação ao cidadão (e-SIC), que atende aos órgãos e entidades do Executivo Federal.

Assim, para organização dos trabalhos, a pesquisa foi dividida nas seguintes etapas:

Figura 1 - Etapas da pesquisa

identificação e seleção dos itens de avaliação do questionário do IG-SEST que estão fundamentados na Lei 13.303/2016 inclusão dos dispositivos dos Decretos Estaduais $32.112 / 2016 \mathrm{e}$ $32.243 / 2017$ nas fundamentações dos itens de avaliação selecionados adequação e seleção final dos itens de avaliação aplicáveis às estatais cearenses aplicação da metodologia de cálculo do IG-SEST, a partir das respostas aos itens de avaliação

Fonte: elaboração própria.

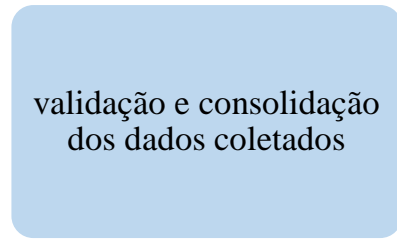

entrevistas na sede das empresas estatais para responder aos questionários e coletar dados e documentos 
Ao final da execução da terceira etapa houve alteração efetiva apenas no item 1 do questionário, que passou a avaliar disposição do artigo 23 da Lei 13.303/2016, mantendo-se alinhado ao que se entendeu por tema amplo do bloco, gestão por metas e resultados, ficando da seguinte forma: “Assunção de compromisso com metas e resultados específicos pelos membros da Diretoria (Lei 13.303/2016, art. 13; e Decreto Estadual 32.243/2017, art. $1^{\text {o }}$, caput)". Isso foi feito porque o item 1 do questionário original do IG-SEST fundamentava-se exclusivamente no Decreto Federal 8.945/2016.

Ademais, a fim de mitigar possíveis confusões na interpretação da lei, quando da realização da pesquisa, foram excluídos do questionário aplicado os itens de avaliação $6,7,8$, $11,12,13,15,16,17,28,34$ e 36 constantes no questionário original do primeiro ciclo de avaliação do IG-SEST, ou por serem amparados em normas aplicáveis exclusivamente no âmbito federal, ou porque o texto do item não possuía correspondência óbvia ao dispositivo da lei indicado. Ainda, houve inclusões pontuais de texto em alguns itens, para deixá-los mais claros e alinhados aos dispositivos legais que os amparam, a exemplo da escrita por extenso da sigla CoAud (Comitê de Auditoria), sem que isso altere o sentido do item ou o seu fundamento.

Dos 33 itens de avaliação que compuseram o questionário final da pesquisa, dispostos no apêndice A, oito foram entendidos como não aplicáveis para as empresas de menor porte operacional, em decorrência da regulamentação disposta no Decreto Estadual 32.112/2016, que flexibiliza as regras da Lei 13.303/2016 para essa categoria de empresa. Não obstante, no decorrer da pesquisa, mesmo o item não sendo aplicável para as empresas de pequeno porte, algumas o responderam como "sim", e, em decorrência disso e como forma de valorizar a proatividade na adoção das regras e mecanismos de governança, a resposta foi assim contabilizada nos resultados.

Na consolidação dos dados, as respostas aos itens de avaliação foram consideradas tais quais fornecidas pelo representante da estatal, de acordo com seu entendimento do texto da lei, buscando-se, na medida do possível, coletar comprovações e evidências do atendimento aos itens de avaliação. Ademais, tendo em vista que foi firmado compromisso de confidencialidade, os nomes das empresas participantes da pesquisa não serão divulgados nos resultados e discussão, sendo representados por letras do alfabeto.

Enfim, o presente estudo caracteriza-se, quanto ao seu objetivo, como uma pesquisa descritiva, tendo em vista que buscou observar, registrar, analisar, classificar e interpretar fatos a partir de técnicas e métodos previamente delimitados; quanto ao seu procedimento, como levantamento, considerando que intentou estruturar a realidade de determinada amostra; e, 
quanto à abordagem do problema, como qualitativo, vez que promovido para analisar, compreender e categorizar processos experimentados por grupos sociais (BEUREN, 2006).

\section{ANÁLISE E DISCUSSÃO DOS RESULTADOS}

Incialmente, informa-se que a pesquisa foi realizada em nove empresas estatais cujo controle acionário pertence (direta ou indiretamente) ao Estado do Ceará, de ambos os tipos societários: empresas públicas e sociedades de economia mista. Dessas estatais, cinco possuíam receita operacional bruta, no último exercício social (2018), superior a $\mathrm{R} \$ 90$ milhões, e as outras quatro, de menor porte operacional, auferiram receita inferior a $\mathrm{R} \$ 90$ milhões.

Destarte, após consolidação das respostas e análise dos resultados, observou-se, conforme gráfico 1, que a média das notas do indicador de governança ficou em 6,49. O resultado é visto com positividade, pois, se enquadrado na classificação de níveis da metodologia do IG-SEST, corresponderia ao segundo melhor nível de governança, sinalizando progresso na maioria das estatais pesquisadas com relação à adequação às regras de governança introduzidas pela Lei 13.303/2016 e respectivos decretos estaduais regulamentadores.

Contrastando as notas do indicador de governança de cada uma das empresas, mostradas no gráfico 1 , verifica-se que a amplitude total das notas é alta, atingindo 8,33, sendo a menor 1,67 e a maior, 10. Sob essa perspectiva, percebe-se uma distância significativa entre algumas estatais e, ainda, os diferentes momentos vivenciados por cada uma delas em relação à implementação dos instrumentos de governança.

Gráfico 1 - Resultado por nota do indicador de governança

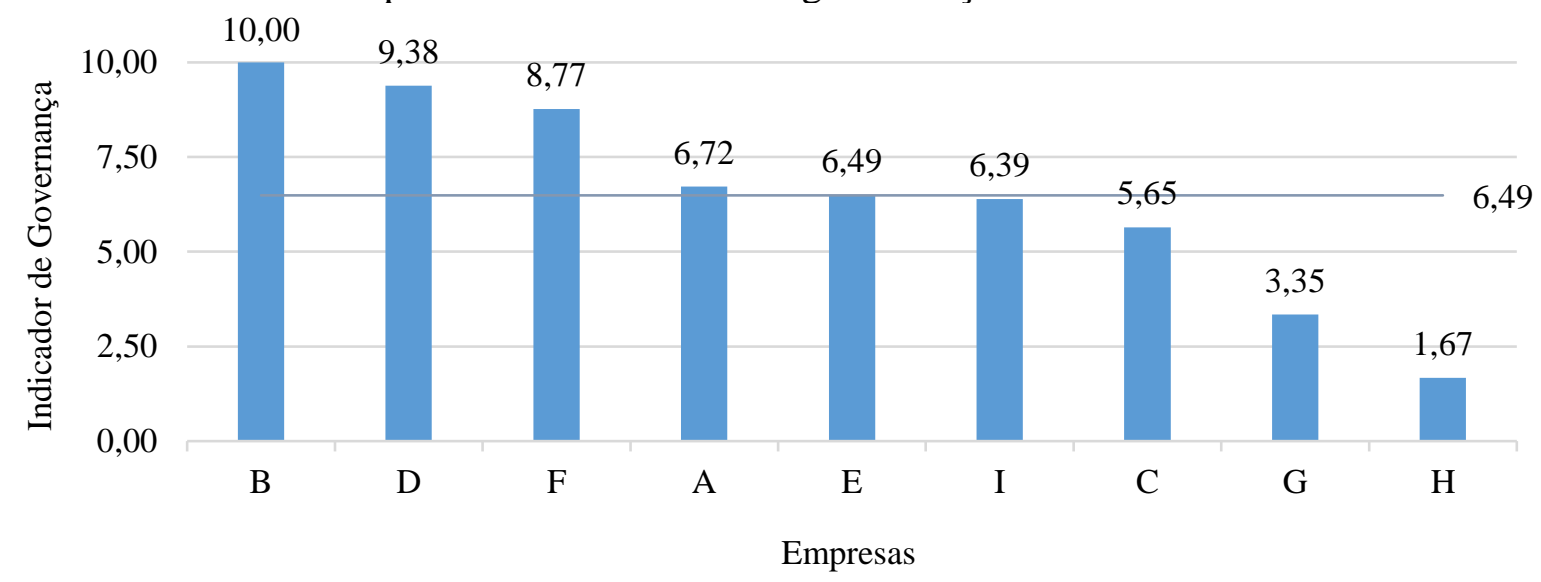

Fonte: elaboração própria com base nos dados da pesquisa. 
O gráfico 2, por sua vez, apresenta os resultados em níveis, sendo possível encontrar exemplares de empresas nos quatro possíveis níveis de governança previstos pela metodologia utilizada, com predominância dos níveis 2 e 3, onde estão concentradas sete das nove empresas estatais pesquisadas.

Gráfico 2 - Resultado por nível de governança

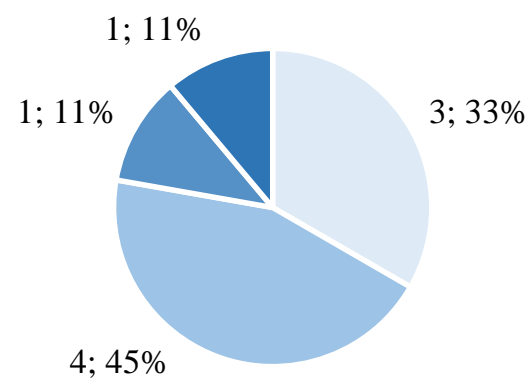

Nível 1 - Nível 2 - Nível 3 - Nível 4

Fonte: elaboração própria com base nos dados da pesquisa.

Já o gráfico 3 e a tabela 1 revelam, para cada estatal, o resultado sob a ótica das dimensões temáticas avaliadas: I) gestão, controle e auditoria; II) transparência das informações; III) conselhos, comitês e diretorias.

Gráfico 3 - Resultado por dimensões

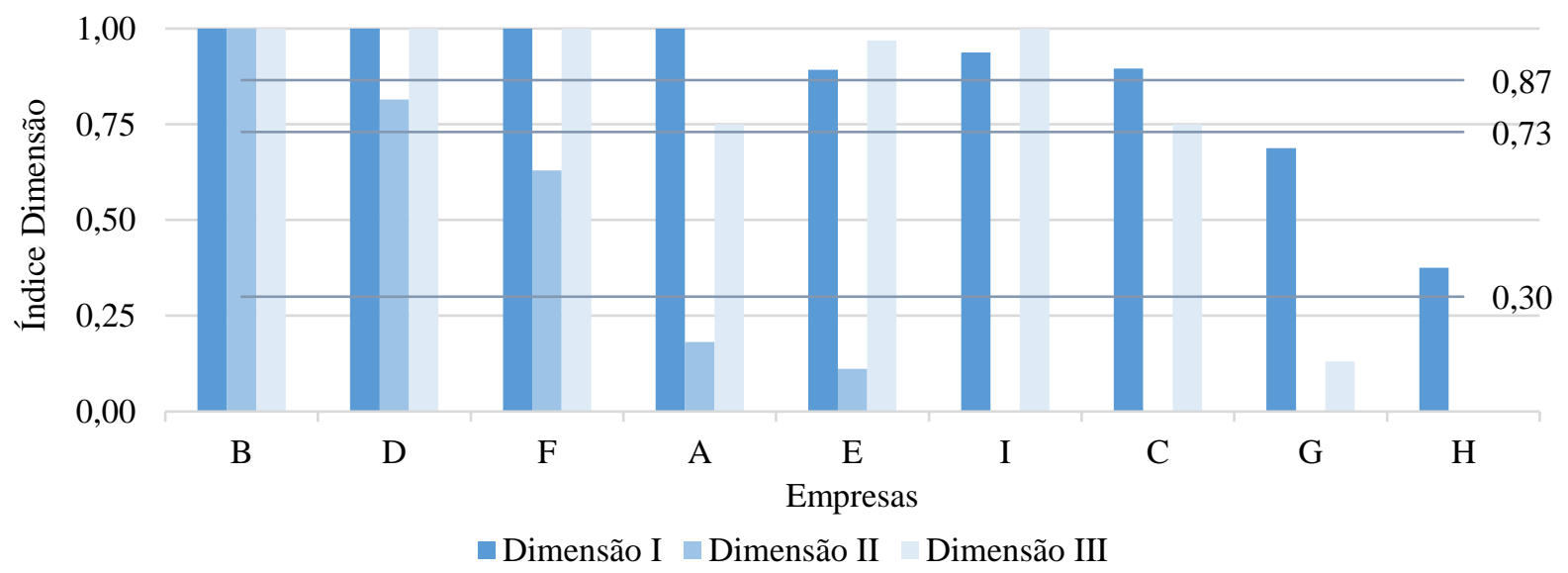

Fonte: elaboração própria com base nos dados da pesquisa.

Tabela 1 - Índice Dimensão

\begin{tabular}{|c|c|c|c|c|c|c|c|c|c|c|}
\hline \multirow{2}{*}{ Dimensões } & \multicolumn{9}{|c|}{ Índice Dimensão das Empresas } & \multirow{2}{*}{ Média } \\
\hline & $\mathbf{A}$ & $\mathbf{B}$ & $\mathbf{C}$ & $\mathbf{D}$ & $\mathbf{E}$ & $\mathbf{F}$ & $\mathbf{G}$ & $\mathbf{H}$ & $\mathbf{I}$ & \\
\hline Dimensão I & 1,00 & 1,00 & 0,90 & 1,00 & 0,89 & 1,00 & 0,69 & 0,38 & 0,94 & 0,87 \\
\hline Dimensão II & 0,18 & 1,00 & 0,00 & 0,81 & 0,11 & 0,63 & 0,00 & 0,00 & 0,00 & 0,30 \\
\hline Dimensão III & 0,75 & 1,00 & 0,75 & 1,00 & 0,97 & 1,00 & 0,13 & 0,00 & 1,00 & 0,73 \\
\hline
\end{tabular}

Fonte: elaboração própria com base nos dados da pesquisa. 
A melhor avaliação, portanto, com média dos resultados de 0,87 , foi a da dimensão I, formada pelos blocos: gestão por metas; gestão de riscos; controle interno; auditoria interna; código de conduta e integridade; e fiscalização da governança das participações minoritárias; nos quais todas as empresas obtiveram alguma pontuação. A resposta é vista com otimismo, pois a dimensão I recebeu peso 4 na construção da metodologia, classificada com grau de relevância alto por ser compreendida como prioritária no primeiro ciclo de avaliação do IGSEST, dada sua relevância na governança das empresas estatais.

Quanto à dimensão III, constituída pelos blocos temáticos: treinamento para administradores; comitês; requisitos e vedações; e membros independentes; verifica-se o segundo melhor resultado, com média de 0,73. Nesses quesitos, percebe-se que apenas duas empresas obtiveram baixo desempenho, uma delas com pontuação de apenas 0,13 e outra que não alcançou nenhum ponto. Essa dimensão foi a que recebeu menos destaque no primeiro ciclo de avaliação do IG-SEST, classificada com grau de relevância baixo (peso 2).

Os resultados com menor média de desempenho, de apenas 0,30, estão na dimensão II, composta de um único bloco temático: requisitos mínimos de transparência. Na metodologia empregada, a dimensão II foi classificada com grau de relevância médio (peso 3), enquanto o bloco que a integra, grau de acurácia alto (peso 3). A despeito dessa graduação, o gráfico 3 e a tabela 1 mostram que das nove empresas pesquisadas, quatro não atingiram qualquer pontuação nessa dimensão, e duas obtiveram pontuação abaixo da média. Inclusive, nela se concentra a maior proporção de itens de avaliação não atendidos, observável no gráfico 4.

Gráfico 4 - Itens de avaliação da dimensão II

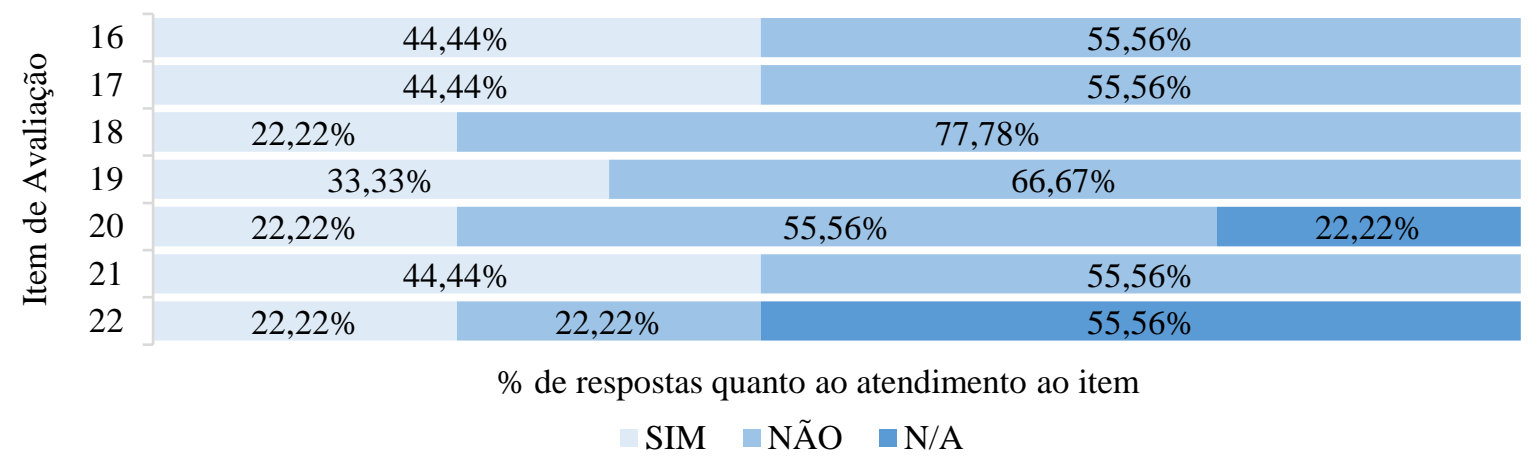

Fonte: elaboração própria com base nos dados da pesquisa.

Chama atenção o baixo atendimento aos itens de avaliação da dimensão transparência das informações, principalmente porque a literatura não considerou o tema como inovação própria da Lei 13.303/2016, diante de legislações já existentes. Uma possível explicação para o caso é encontrada na ponderação dos itens de avaliação que constituem o bloco requisitos 
mínimos de transparência. Dos sete itens que o compõe, quatro foram classificados com grau de complexidade alto (peso 5), indicando que as ações que viabilizam o atendimento ao item apresentam maior nível de dificuldade para implementação.

Em uma perspectiva mais detalhada, os resultados podem ser visualizados no gráfico 5 e tabela 2 pelo ângulo dos blocos temáticos, demonstrando que: requisitos mínimos de transparência e treinamento para administradores, com médias respectivas de 0,30 e 0,53, obtiveram os menores resultados para o índice bloco.

Gráfico 5 - Médias do Índice Bloco

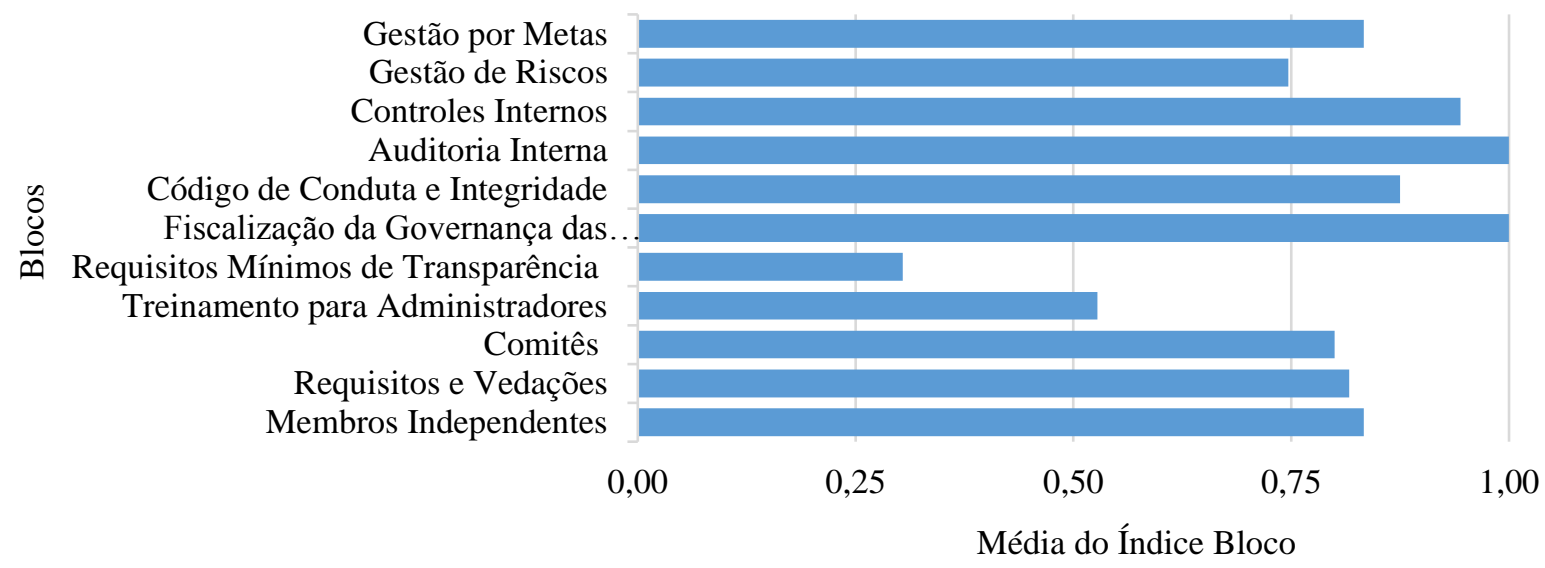

Fonte: elaboração própria com base nos dados da pesquisa.

Tabela 2 - Índice Bloco

\begin{tabular}{|c|c|c|c|c|c|c|c|c|c|c|}
\hline \multirow{2}{*}{ Blocos } & \multicolumn{9}{|c|}{ Índice Bloco das Empresas } & \multirow{2}{*}{ Média } \\
\hline & $\mathbf{A}$ & B & $\mathbf{C}$ & D & $\mathbf{E}$ & $\mathbf{F}$ & $\mathbf{G}$ & $\mathbf{H}$ & $\mathbf{I}$ & \\
\hline Gestão por Metas & 1,00 & 1,00 & N/A & 1,00 & 0,00 & 1,00 & 1,00 & N/A & N/A & 0,83 \\
\hline Gestão de Riscos & 1,00 & 1,00 & 0,72 & 1,00 & 1,00 & 1,00 & 0,00 & 0,00 & 1,00 & 0,75 \\
\hline Controles Internos & 1,00 & 1,00 & 1,00 & 1,00 & 1,00 & 1,00 & 1,00 & 0,50 & 1,00 & 0,94 \\
\hline Auditoria Interna & N/A & 1,00 & N/A & 1,00 & 1,00 & 1,00 & 1,00 & N/A & N/A & 1,00 \\
\hline $\begin{array}{l}\text { Código de Conduta e } \\
\text { Integridade }\end{array}$ & 1,00 & 1,00 & 1,00 & 1,00 & 0,75 & 1,00 & 0,63 & 0,75 & 0,75 & 0,88 \\
\hline $\begin{array}{l}\text { Fiscalização da } \\
\text { Governança das } \\
\text { Participações } \\
\text { Minoritárias }\end{array}$ & N/A & N/A & N/A & N/A & 1,00 & N/A & N/A & N/A & N/A & 1,00 \\
\hline $\begin{array}{l}\text { Requisitos Mínimos de } \\
\text { Transparência }\end{array}$ & 0,18 & 1,00 & 0,00 & 0,81 & 0,11 & 0,63 & 0,00 & 0,00 & 0,00 & 0,30 \\
\hline $\begin{array}{l}\text { Treinamento para } \\
\text { Administradores }\end{array}$ & 0,00 & 1,00 & 0,00 & 1,00 & 0,75 & 1,00 & 0,00 & 0,00 & 1,00 & 0,53 \\
\hline Comitês & N/A & 1,00 & N/A & 1,00 & 1,00 & 1,00 & 0,00 & N/A & N/A & 0,80 \\
\hline Requisitos e Vedações & 1,00 & 1,00 & 1,00 & 1,00 & 1,00 & 1,00 & 0,35 & 0,00 & 1,00 & 0,82 \\
\hline $\begin{array}{l}\text { Membros } \\
\text { Independentes }\end{array}$ & N/A & 1,00 & N/A & 1,00 & 1,00 & 1,00 & 0,00 & N/A & 1,00 & 0,83 \\
\hline
\end{tabular}

Fonte: elaboração própria com base nos dados da pesquisa. 
Por fim, sobre a criticidade do item de avaliação no contexto da governança, mensurada a partir dos pesos dos: item, bloco e dimensão, verifica-se que os itens com grau de criticidade mais alto, e, portanto, merecedores de maior atenção por parte das empresas, estão inseridos nas dimensões I e II. No gráfico 6 percebe-se menor aderência nos itens 18, 19 e 20, que compõem a dimensão transparência das informações, como já destacados anteriormente no gráfico 4.

Gráfico 6 - Itens de avaliação com grau de criticidade alto

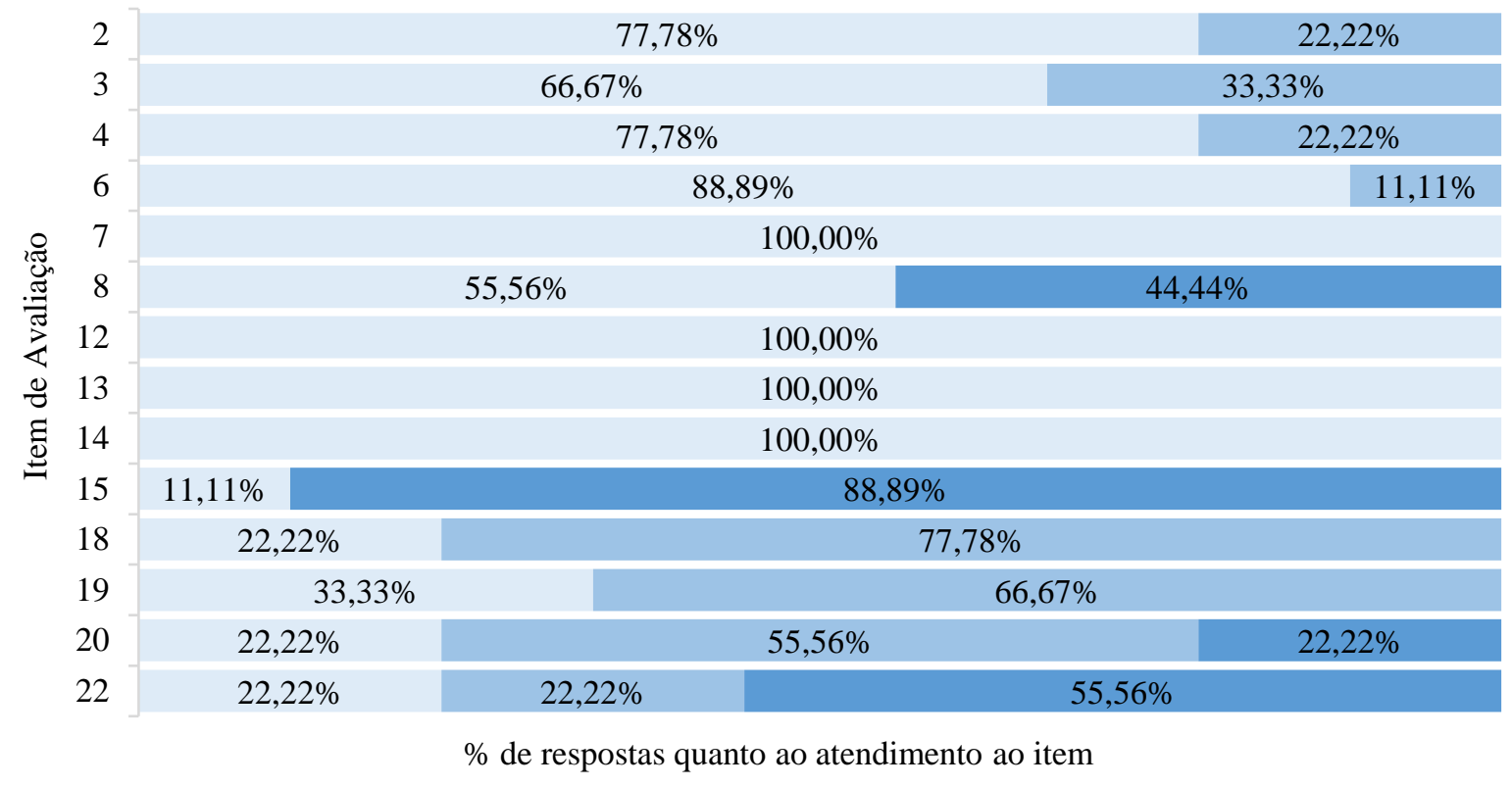

Fonte: elaboração própria com base nos dados da pesquisa.

Como explicado na metodologia, as respostas aos itens de avaliação foram consideradas na forma respondida pelas estatais que se predispuseram a participar da pesquisa. Inclusive, no quadro 5, estão dispostos os itens respondidos com "sim" pelas estatais, e que, após circularização no site da empresa e nos documentos fornecidos, o atendimento ao item não foi confirmado. Contudo, entende-se natural, no campo da pesquisa científica, as divergências interpretativas que venham a provocar pequena variação nos resultados, ainda mais porque, como toda inovação legislativa, a Lei 13.303/2016 ainda se submeterá a diversas discussões jurisprudenciais e doutrinárias.

Quadro 5 - Itens não evidenciados ou evidenciados parcialmente

\begin{tabular}{|l|l|}
\hline Item & Empresa \\
\hline 21 & B, D \\
\hline 27 & C \\
\hline 29 & A, C e G \\
\hline
\end{tabular}

Fonte: elaboração própria. 
Interessa esclarecer que a pesquisa que deu origem ao presente trabalho foi realizada com base na Lei 13.303/2016 e Decretos Estaduais 32.243/2017 e 32.112/2016. Não obstante, este último, que trata das empresas de pequeno porte, sofreu alterações, em 25/06/2018, mediante Decreto Estadual 32.722/2018. Nessa ocasião, destaca-se a alteração do artigo $9^{\circ}, \S 1^{\circ}$, que reflete na obrigatoriedade de atendimento ao item 22 também pelas estatais de menor porte operacional, o que foi considerado "N/A" (não aplicável) na execução do questionário.

Diante disso, informa-se que, caso a resposta das quatro empresas de pequeno porte pesquisadas fosse "sim" para o item 22, o resultado da nota geral do indicador aumentaria, porém não o suficiente para fazê-las galgar melhor nível de governança. Por outro lado, a resposta sendo "não", haveria uma pequena redução da nota em apenas uma dessas empresas, sem alterações nas outras três, igualmente se mantendo a classificação inicial dos níveis de governança. Isso se explica porque o item 22 compõe bloco e dimensão para os quais essas estatais já não haviam atingido nenhuma pontuação.

Ressalta-se que das nove empresas participantes, sete já haviam promovido alterações em seus estatutos sociais após a edição da Lei 13.303/2016 e respectivos decretos estaduais regulamentadores, passo primordial na direção da implementação dos mecanismos de governança instituídos pela nova ordem jurídica. Não obstante, em duas permanecem vigentes os estatutos sociais anteriores, que não atendem a contento às inovações legislativas, o que, por sinal, pode ter contribuído para o baixo desempenho dessas empresas. Inclusive, essa omissão pode encontrar razão na morosidade do setor público relatada nos estudos de Silva F. (2018).

Os resultados de melhor desempenho desta pesquisa, que se concentram nos requisitos legais que instituem: instâncias de controle (dimensão I), criação de comitês estatutários, requisitos e vedações para nomeação dos agentes da governança e previsão de membros independentes no Conselho (dimensão III), denotam que as práticas de governança adotadas pela maior parte das estatais cearenses estão alinhadas ao que Faria e Streit (2016) consideram como essencial para a boa governança e credibilidade de organizações públicas, os quais contribuem para o abrandamento de possíveis conflitos de agência (NUNES, 2016).

Os avanços relacionados às práticas e mecanismos de governança já implementados pelas estatais cearenses podem ser explicados tanto pela preexistência de leis que tratavam de algum aspecto da governança (SILVA F., 2018; FORTINI; SHERMAM, 2017), como pelo fato de já ter se encerrado o prazo legal de adequação à Lei 13.303/2016. Tal situação reflete as pressões coercitivas da teoria institucional, que exercem maior influência nas entidades devido ao poder sancionador decorrente do descumprimento das legislações (OLIVEIRA et al., 2017). 
Por outro lado, a despeito de Faria e Streit (2016) destacarem a transparência como pilar da boa governança, considerando que proporciona previsibilidade, maior fiscalização e controle (SILVA, F., 2018), os resultados desta pesquisa para a divulgação dos requisitos de transparência (dimensão II) revelaram baixo desempenho pela maioria das empresas.

Finalizando a discussão, oportuno mencionar Fortini e Shermam (2017), que concluíram, apesar dos avanços, pela necessidade de efetiva implementação e fomento das medidas de governança inseridas nas legislações para surtir os efeitos esperados de aprimoramento da gestão pública, o que pode ser reforçado pelos órgãos de controle interno e externo ao exercerem as atribuições introduzidas no capítulo III da Lei 13.303/2016 (da fiscalização pelo Estado e pela sociedade).

\section{CONSIDERAÇÕES FINAIS}

O novo marco regulatório das estatais introduz uma série de mecanismos e instrumentos de governança, notadamente relacionados à transparência das informações, estruturas de controle e profissionalização dos administradores, com o intuito de alavancar o desempenho dessas empresas e mitigar riscos relacionados a interferências políticas, corrupção e utilidades pessoais, próprios do conflito de agências no contexto das organizações públicas, aumentando a confiança e credibilidade junto à sociedade e demais partes interessadas.

$\mathrm{Na}$ pesquisa realizada, adaptada com base na metodologia proposta pela SEST, foi possível identificar qual o nível de governança das empresas estatais sob controle acionário do Estado do Ceará à luz das regras de governança instituídas na Lei 13.303/2016 e nos decretos estaduais regulamentadores, tendo sido diagnosticado que $78 \%$ das empresas estatais participantes foram enquadradas nos níveis 1 e 2 (nota > 5,09), considerados os melhores níveis de governança de acordo com a metodologia.

Isso denota bom desempenho em diversos itens de avaliação depurados dessas normas, notadamente os atinentes à instituição de estruturas de controle e gestão de riscos e à contratualização de regras nos estatutos sociais, que contribuem na conciliação dos interesses da relação agente-principal e na mitigação do problema de agência.

A despeito disso, constatou-se que, apesar de encerrado o prazo legal para implementação das regras e mecanismos de governança instituídos na Lei 13.303/2016, algumas empresas pouco caminharam nesse sentido, pendente inclusive o que se percebe como 
início do processo, que seria a adaptação estatutária com observância das regras de governança, transparência e estruturas, gestão de riscos e controles internos, como dispõe o $\operatorname{artigo~} 6^{\circ}$ da lei.

Os resultados destacam ainda que o desempenho geral que mais deixou a desejar ficou por conta da dimensão II, abrangendo o tema transparência das informações, em que a média do índice dimensão de todas as empresas foi de apenas 0,30, em um espectro que varia entre 0 e 1 , sendo evidenciado que 44,44\% das empresas sequer pontuaram nos itens de avaliação desse tema e 22,22\% obtiveram pontuação mínima, inclusive aquém da média já considerada baixa.

Esse diagnóstico posiciona a realidade da governança das estatais cearenses e evidencia as oportunidades de aprimoramento quanto à aderência aos mecanismos e práticas legais de governança, recorrentemente ressaltadas pela literatura como medidas para resolução do conflito de agência e como termômetro para a confiança e a atração de investidores, afetando diretamente o valor dessas organizações.

O diagnóstico demonstra também que as práticas de governança adotadas são evidências de confirmação da teoria institucional, no que se refere as ações derivadas de pressões institucionais do ambiente sobre as entidades, a partir da visão coercitiva e de conformidade legal, reforçando a conexão entre a teoria e a prática no desenvolvimento de debates e pesquisas sobre governança no setor público.

Nesse contexto, como tema para futuros trabalhos, sugere-se a reaplicação do questionário para avaliar, comparativamente, a evolução das empresas num dado recorte de tempo, ou, ainda, um upgrade da avaliação para alcançar não apenas o aspecto da conformidade com a Lei 13.303/2016 e os regulamentos, mas também o viés operacional, o que inclusive já é realizado pela Secretaria de Coordenação e Governança das Empresas Estatais. Além disso, pode-se investigar a relação existente entre as práticas de governança adotadas, ou não, e o desempenho observado nessas empresas, inclusive o desempenho de políticas públicas a elas associadas.

\section{REFERÊNCIAS}

ALTOUNIAN, C. S.; SOUZA, D. L.; LAPA, L. R. G. Gestão e governança pública para resultados: uma visão prática. Belo Horizonte: Fórum, 2017.

ANTUNES, G. A. Estatuto jurídico das empresas estatais: Lei $n^{\circ}$ 13.303/2016 comentada. Belo Horizonte: Fórum, 2017. 
BEUREN, I. M. Como elaborar trabalhos monográficos em contabilidade: teoria e prática. 3. Ed. São Paulo: Atlas, 2006.

BICALHO, A. P. N. Lei de Responsabilidade das estatais: fomento e perspectivas às estatais prestadoras de serviço público de saneamento básico. Coluna Jurídica da Administração Pública. [S.l.]: JML Consultoria \& Eventos, 2017. Disponível em: $<$ https://www.jmleventos.com.br/pagina.php?area=coluna-

juridica\&acao=download\&dp_id=164>. Acesso em: 09 jun. 2019.

BRASIL. Lei ${ }^{\circ} 13.303$, de 30 de junho de 2016. Dispõe sobre o estatuto jurídico da empresa pública, da sociedade de economia mista e de suas subsidiárias, no âmbito da União, dos Estados, do Distrito Federal e dos Municípios. Diário Oficial da União, Brasília, DF, 01 de julho. 2016.

BRASIL. Ministério da Economia. Empresas Estatais IG-SEST. Disponível em: <http://www.planejamento.gov.br/empresas-estatais-igsest/certificacoes-ig-sest>. Acesso em: 09 jul. 2019.

BRASIL. Tribunal de Contas de União. Relatório de levantamento n ${ }^{\circ}$ TC 020.830/2014-9. AC1273-19/15-P. Relator: Augusto Nardes. Brasília, DF, 27 de maio de 2015. Disponível em: <https://contas.tcu.gov.br/sagas/SvlVisualizarRelVotoAcRtf? codFiltro=SAGAS-SESSAOENCERRADA\&seOcultaPagina=S\&item0=523751 >. Acesso em: 05 jun. 2019.

CAMARGO, A. A. S. A diretoria, o comitê de auditoria estatutário e o conselho fiscal na lei $\mathrm{n}^{\circ}$ 13.303/2016: primeiras reflexões. In: NORONHA, J. O; FRAZÃO, A.; MESQUITA, D. A. (Coord.). Estatuto jurídico das estatais: análise da lei $n^{\circ}$ 13.303/2016, Belo Horizonte: Fórum, 2017. p. 171-182.

CEARÁ. Decreto ${ }^{\circ}$ 32.112, de 23 de dezembro de 2016. Dispõe sobre regras de governança para empresas públicas e sociedades de economia mista estaduais na forma do $\S 3^{\circ}$, art. $1^{\circ}$, da Lei Federal $n^{\circ} 13.303$, de 30 de junho de 2016, e dá outras providências. Diário Oficial do Estado, Fortaleza, CE, 27 de dezembro. 2016.

CEARÁ. Decreto ${ }^{\circ}$ 32.243, de 31 de maio de 2017. Dispõe sobre a aplicação, no âmbito estadual, da Lei Federal $\mathrm{n}^{\circ}$ 13.303, de 30 de junho de 2016, para as empresas públicas e sociedades de economia mista do Estado do Ceará de maior receita operacional. Diário Oficial do Estado, Fortaleza, CE, 01 de junho. 2017.

CEARÁ. Decreto n ${ }^{\circ} 32.722$, de 25 de junho de 2018. Altera o Decreto $n^{\circ} 32.112$, de 23 de dezembro de 2016, e dá outras providências. Diário Oficial do Estado, Fortaleza, CE, 25 de junho. 2018.

CEARÁ. Governo do Estado do Ceará. Organograma estadual. Disponível em: <https://www.ceara.gov.br/organograma/>. Acesso em: 01 jun. 2019.

FARIA, F. A.; STREIT, R. E. Governança em bancos centrais: um estudo comparativo das práticas de governança dos bancos centrais do Brasil, Canadá e Inglaterra. Revista de Administração Pública, v. 50, n. 5, p. 765-794, 2016, <http://dx.doi.org/10.1590/00347612143480>. 
FERRAZ, S. Das regras de governança corporativa, transparência e gestão de riscos. Revista de Direito Administrativo e Infraestrutura, v. 7, n. 29, p. 109-137, 2018.

FERREIRA, R. M. et al. Governança corporativa: um estudo bibliométrico da produção científica entre 2010 a 2016. Organizações em Contexto, v. 15, n. 29, p. 323-342, 2019, <http://dx.doi.org/10.15603/1982-8756/roc. v15n29p323-342>.

FONTES FILHO, J. R. A governança corporativa em empresas estatais brasileiras frente a lei de responsabilidade das estatais (Lei no 13.303/2016). Revista do Serviço Público, v. 69, p. 209-238, 2018, <https://doi.org/10.21874/rsp.v69i0>.

FONTES FILHO, J. R; PICOLIN, L. M. Governança corporativa em empresas estatais: avanços, propostas e limitações. Revista de Administração Pública, v. 42, n. 6, p. 1163-1188, 2008.

FORTINI, C.; SHERMAM, A. Governança pública e combate à corrupção: novas perspectivas para o controle da Administração Pública brasileira. Interesse Público, Belo Horizonte, ano 19, n. 102, p. 27-44, 2017.

IBGC - Instituto Brasileiro de Governança Corporativa. Código das melhores práticas de governança corporativa. 5. Ed. São Paulo, 2015. Disponível em: <https://conhecimento.ibgc.org.br/Paginas/Publicacao.aspx?PubId=21138>. Acesso em: 06 jun. 2019.

IBGC - Instituto Brasileiro de Governança Corporativa. Governança corporativa em empresas estatais listadas no Brasil. 1. Ed. São Paulo, 2017. Disponível em: <https://www.ibgc.org.br/userfiles/files/Publicacoes/IBGC_Pesquisa/Publicacao-

IBGCPesquisa-GC_SEMs-2017.pdf >. Acesso em: 06 jun. 2019.

IFAC - International Federation of Accountants. Good Governance in the Public Sector Consultation Draft for an International Framework. [New York], 2013. Disponível em: <http://www.ifac.org/system/files/publications/files/Good-Governance-in-the-PublicSector.pdf $>$. Acesso em: 06 jun. 2019.

JENSEN, M.; MECKLING, W. Theory of the firm: managerial behavior, agency costs and ownership structure. Journal of Financial Economics, v. 3, n. 4, p. 305-360, 1976, <https://doi.org/10.1016/0304-405X (76) 90026-X>.

KOPPELL, J. G. S. Pathologies of accountability: ICANN and the challenge of "multiple accountabilities disorder". Public Administration Review, v. 5, n. 1, p. 94-108, 2005, <https://doi.org/10.1111/j.1540-6210.2005.00434.x>.

LIMA, L. C. et al. Práticas de governança corporativa adotadas e divulgadas pelos fundos de pensão brasileiros. Revista Contemporânea de Contabilidade, v. 12, n. 27, p. 03-26, 2015, <http://dx.doi.org/10.5007/2175-8069.2015v12n27p3>.

LUPION, R. Estatuto jurídico das estatais: governança além da forma. Revista de Estudos e Pesquisas Avançadas do Terceiro Setor, v. 5, n. 1, p. 125-165, 2018, <http://dx.doi.org/10.31501/repats.v5i1.9773>. 
MARTINS, H. A implementação de medidas de governança corporativa trazidas pela Lei $\mathrm{n}^{\circ}$ 13.303/2016 e principais impactos nas empresas estatais de menor porte. Revista de Direito Público da Economia, v. 16, n. 61, p. 93-118, 2018.

MATIAS-PEREIRA, J. Governança no setor público. São Paulo: Atlas, 2010.

MAXIMIANO, G. Aplicação de regras de compliance à luz da Lei no 13.303/2016. Raízes Jurídicas, v. 9, n. 2, p. 211-232, 2017.

NARDES, A. Da governança à esperança. Belo Horizonte: Fórum, 2018.

NUNES, P. R. C. Práticas de governança, fatores institucionais e empresariais e o desempenho na prestação de serviços públicos no setor de saneamento básico. Tese (Doutorado em Administração de Empresas) - Universidade de Fortaleza, Fortaleza, Brasil, 2016.

OCDE - Organização para Cooperação e Desenvolvimento Econômico. Diretrizes da OCDE sobre governança corporativa de empresas estatais. Paris: OCDE, 2015, <https://doi.org/10.1787/9789264181106-pt>.

OCDE - Organização para Cooperação e Desenvolvimento Econômico. Princípios de governo das sociedades do G20 e da OCDE. Paris: OCDE, 2016, <http://dx.doi.org/10.1787/9789264259195-pt>.

OECD - Organisation for Economic Co-operation and Development. OECD principles of corporate governance. Paris: OECD, 1999. Disponível em: <https://www.oecd.org/officialdocuments/publicdisplaydocumentpdf/?cote=C/MIN 6\&docLanguage=En>. Acesso em 09 jul. 2019.

OLIVEIRA, D. T.; TAZINASSO, L. Governança pública: os indicadores de governança mundial dos sete países de maior economia do mundo. In: CONGRESSO INTERNACIONAL DE ADMINISTRAÇÃO - ADM 2015, Ponta Grossa. Anais eletrônicos... [S. l: s. n. ], 2015. Disponível em: <http://www.admpg.com.br/2015/down.php?id=1818\&q=1>. Acesso em: 30 jun. 2019.

OLIVEIRA, M. C.; CEGLIA, D.; ANTONIO FILHO, F. Analysis of corporate governance disclosure: a study through BRICS countries. Corporate Governance, v. 16, n. 5, p. 923-940, 2016, <https://doi.org/10.1108/CG-12-2015-0159>.

OLIVEIRA, M. C. et al. Analysis of corporate governance disclosure: a study on Brazilian companies. Contextus - Revista Contemporânea de Economia e Gestão, v. 15, n. 1, p. 172194, 2017, <https://doi.org/10.19094/contextus.v15i1.945>.

PINHO, C. A. B. Considerações sobre um ano de vigência do sistema de contratação na lei de empresas estatais (Lei n ${ }^{\circ}$ 13.303/2016). Revista de Contratos Públicos, ano 6, n. 11, p. 35-54, 2017.

RIBEIRO NETO, M. et al. Indicador de governança corporativa como instrumento de avaliação da política pública. Boletim de Análise Político-Institucional, n. 15, p. 71-78, 2018. Disponível em: 
<http://www.ipea.gov.br/portal/images/stories/PDFs/boletim_analise_politico/180905_bapi_1 5_cap07.pdf >. Acesso em: 23 jun. 2019.

ROSSETTI, J. P.; ANDRADE, A. Governança corporativa: fundamentos, desenvolvimento e tendências. 7. Ed. São Paulo: Atlas, 2019.

SCOTT, W. R. Approaching adulthood: the maturing of institutional theory. Theory and Society, v. 37, n. 5, p. 427-442, 2008 <https://doi.org/10.1007/s11186-008-9067-z>.

SEST - Secretaria de Coordenação e Governança das Empresas Estatais. Indicador de governança IG-SEST: regulamento. [Brasília]: SEST, 2017. Primeiro ciclo de avaliação.

SEST - Secretaria de Coordenação e Governança das Empresas Estatais. Indicador de governança IG-SEST: regulamento. [Brasília]: SEST, 2019. Quarto ciclo de avaliação. Disponível em: <http://www.planejamento.gov.br/empresas-estatais-igsest/regulamento-igsest-4ociclo-versao-final.pdf >. Acesso em: 09 jul. 2019.

SILVA, E. C. Governança corporativa nas empresas: guia prático de orientação para acionistas, investidores, conselheiros de administração e fiscal, auditores, executivos, gestores, analistas de marcado e pesquisadores. 4. Ed. São Paulo: Atlas, 2016.

SILVA, F. D. Implantação da lei $\mathbf{n}^{\mathbf{0}} \mathbf{1 3 . 3 0 3 / 1 6}$ de governança corporativa: um estudo do impacto no desempenho das empresas estatais. Dissertação (Mestrado em Economia e Finanças) - Fundação Getúlio Vargas, São Paulo, Brasil, 2018.

SILVA, J. P. C. Oportunidades de avanço institucional na governança das estatais brasileiras. Dissertação (Mestrado em Políticas Públicas e Desenvolvimento) - Instituto de Pesquisa Econômica Aplicada, Brasília, Brasil, 2018.

TCU - Tribunal de Contas da União. Referencial básico de governança: aplicável a órgãos e entidades da administração pública. Brasília: TCU, 2014. Disponível em: <https://portal.tcu.gov.br/lumis/portal/file/fileDownload.jsp?inline=1\&fileId=8A8182A24F0 A728E014F0B34D331418D>. Acesso em: 23 jun. 2019.

ZYMLER, B. Considerações sobre o estatuto jurídico das empresas estatais (Lei 13.303/2016). Interesse Público, ano 19, n. 102, p. 15-26, 2017. 


\section{APÊNDICE A - DESCRIÇÃO DOS ITENS DE AVALIAÇÃO E PESOS}

\section{DIMENSÃo I: GESTÃo, CONTROLE E AUDITORIA - Peso 4}

\section{Bloco 1.1 - Gestão por Metas - Peso 1}

1. Assunção de compromisso com metas e resultados específicos pelos membros da Diretoria (Lei 13.303/16, art. 23; Decreto 32.243/17, art. $1^{\circ}$, caput). Peso 1

\section{Bloco 1.2 - Gestão de Riscos - Peso 3}

2. Possui área responsável pela gestão de riscos (Lei 13.303/16, art. $9^{\circ}$, II e $\S 2^{\circ}$; Decreto 32.112/16, art. $2^{\circ}$, I; Decreto 32.243/17, art. $1^{\circ}$, caput). Peso 5

3. Possui área responsável pela gestão de riscos segregada das demais atividades (Lei $13.303 / 16$, art. $9^{\circ}$, II e $\S 2^{\circ}$; Decretos $32.112 / 16$, art. $2^{\circ}$, II e $\$ 4^{\circ}$, e $32.243 / 17$, art. $1^{\circ}$ ). Peso 5

4. Possui área responsável gestão de riscos vinculada ao Diretor-Presidente (Lei 13.303/16, art. $9^{\circ}$, II e $\S 2^{\circ}$; Decretos 32.112/16, art. $2^{\circ}, \S^{\circ}, 32.243 / 17$, art. $1^{\circ}$ ). Peso 5

5. Possui área responsável de gestão de riscos liderada por Diretor-Presidente ou Diretor Estatutário (Lei 13.303/16, art. $9^{\circ}$, II e $\S 2^{\circ}$; Decretos 32.112/16, art. $2^{\circ}$, $\S 4^{\circ}$, e $32.243 / 17$, art. $\left.1^{\circ}\right)$. Peso 3

Bloco 1.3 - Controles Internos - Peso 3

6. Implementa práticas cotidianas de Controles Internos para os seus administradores (Lei 13.303/16, art. $9^{\circ}$, I; Decretos 32.112/16, art. $2^{\circ}$, I, e 32.243/17, art. $1^{\circ}$ ). Peso 5

7. Implementa práticas cotidianas de Controles Internos, para os seus empregados (Lei 13.303/16, art. $9^{\circ}$, I; Decretos 32.112/16, art. $2^{\circ}$, I, e 32.243/17, art. $1^{\circ}$ ). Peso 5

\section{Bloco 1.4 - Auditoria Interna - Peso 3}

8. A Auditoria Interna é vinculada ao Conselho de Administração (Lei 13.303/16, art. $9^{\circ}$, $\S 3^{\circ}$; Decreto $32.243 / 17$, art. $1^{\circ}$ ). Peso 5

\section{Bloco 1.5 - Código de Conduta e Integridade - Peso 2}

9. Possui e divulga o Código de Conduta e Integridade na forma prevista na Lei 13.303/16, art. $9^{\circ}, \S 1^{\circ}$, e Decretos $32.112 / 16$, art. $2^{\circ}$, $\S \S 1^{\circ}$ e $2^{\circ}$, e $32.243 / 17$, art. $1^{\circ}$ ). Peso 3

10. Realiza treinamentos periódicos sobre o tema aos administradores (Lei 13.303/2016, art. $9^{\circ}$, $\S 1^{\circ}$, VI; Decretos 32.112/16, art. $2^{\circ}$, $\S 2^{\circ}$, VI, e 32.243/17, art. $1^{\circ}$ ). Peso 3

11. Realiza treinamentos periódicos sobre o tema aos empregados (Lei 13.303/2016, art. $9^{\circ}$, $\S 1^{\circ}, \mathrm{VI}$; Decretos $32.112 / 16$, art. $2^{\circ}$, $\S 2^{\circ}$, VI, e $32.243 / 17$, art. $\left.1^{\circ}\right)$. Peso 3

12. Disponibiliza canal que possibilite o recebimento de denúncias internas relativas ao seu descumprimento, bem como das demais normas internas de ética e obrigacionais (Lei 13.303/16, art. $9^{\circ}, \S 1^{\circ}$, III; Decretos 32.112/16, art. $2^{\circ}, \S 2^{\circ}$, III, e 32.243/17, art. $1^{\circ}$ ). Peso 5

13. Disponibiliza canal que possibilite o recebimento de denúncias externas relativas ao seu descumprimento, bem como das demais normas externas de ética e obrigacionais (Lei 13.303/16, art. $9^{\circ}, \S 1^{\circ}$, III; Decretos 32.112/16, art. $2^{\circ}, \S 2^{\circ}$, III, e 32.243/17, art. $1^{\circ}$ ). Peso 5

14. Dispõem de mecanismos de proteção que impeçam qualquer espécie de retaliação à pessoa que utilize o canal de denúncias (Lei 13.303/16, art. $9^{\circ}$, $\S 1^{\circ}$, IV; Decretos 32.112/16, art. $2^{\circ}, \S 2^{\circ}$, IV, e $32.243 / 17$, art. $\left.1^{\circ}\right)$. Peso 5

Bloco 1.6 - Fiscalização da Governança das Participações Minoritárias - Peso 2

15. Adota, no dever de fiscalizar, práticas de governança e controle nas subsidiárias não controladas (Lei 13.303/16, art. $1^{\circ}, \S 7^{\circ}$; Decreto 32.243/17, art. $1^{\circ}$ ). Peso 5 


\section{DIMENSÃO II: TRANSPARÊNCIA DAS INFORMAÇÕES - Peso 3}

\section{Bloco 2.1 - Requisitos Mínimos de Transparência - Peso 3}

16. Publica a Carta Anual de Governança Corporativa em seu sítio eletrônico (Lei 13.303/16, art. $8^{\circ}$, VIII e $\S 4^{\circ}$, art. $1^{\circ}, \S 1^{\circ}$; Decreto $32.243 / 17$, art. $1^{\circ}$ ). Peso 1

17. Disponibiliza ao público a Política de Divulgação de Informações Relevantes (Lei $13.303 / 16$, art. $8^{\circ}$, IV e $\S 4^{\circ}$, e art. $1^{\circ}, \S 1^{\circ}$; e Decreto $32.243 / 17$, art. $1^{\circ}$ ). Peso 3

18. Divulga Relatório Integrado ou de Sustentabilidade (Lei 13.303/16, art. $8^{\circ}$, IX e $\S 4^{\circ}$, art. $1^{\circ}$, $\S 1^{\circ}$; Decreto 32.243/17, art. $\left.1^{\circ}\right)$. Peso 5

19. Divulga a Política de Transações com Partes Relacionadas (Lei 13.303/16, art. $8^{\circ}$, VII e $\S 4^{\circ}$, art. $1^{\circ}, \S 1^{\circ}$; e Decreto $32.243 / 17$, art. $1^{\circ}$ ). Peso 5

20. Divulga Política de Dividendos por canal acessível aos acionistas e ao público em geral (Lei $13.303 / 16$, art. $8^{\circ}, \mathrm{V}$ e $\S 4^{\circ}$, art. $1^{\circ}, \S 1^{\circ}$; e Decreto $32.243 / 17$, art. $1^{\circ}$ ). Peso 5

21. Mantém acessível ao público toda e qualquer remuneração de seus administradores e conselheiros (Lei 13.303/16, art. $8^{\circ}$, III e $\S 4^{\circ}$, art. 12, I, art. $1^{\circ}, \S 1^{\circ}$; Decreto 32.243/17, art. $\left.1^{\circ}\right)$. Peso 3

22. Divulga as conclusões da análise realizada pelo CA sobre o atendimento das metas e dos resultados na execução do Plano de Negócios e da Estratégia (Lei 13.303/16, art. 23, §2 e $\S 3^{\circ}$; Decreto $32.243 / 17$, art. $1^{\circ}$ ). Peso 5

\section{DIMENSÃO III: CONSELHOS, COMITÊS E DIRETORIAS - Peso 2}

\section{Bloco 3.1 - Treinamento para Administradores - Peso 1}

23. Os administradores (membros do Conselho de Administração e da Diretoria) recebem treinamento específico na posse (Lei 13.303/16, art. 17, $\S 4^{\circ}$; Decretos 32.112/16, art. $6^{\circ}$, $\S 2^{\circ}$, e $32.243 / 17$, art. $\left.1^{\circ}\right)$. Peso 3

24. Os administradores (membros do Conselho de Administração e da Diretoria) recebem treinamento específico anualmente (Lei 13.303/16, art. 17, $\S 4^{\circ}$; Decretos 32.112/16, art. $6^{\circ}$, $\S 2^{\circ}$, e $32.243 / 17$, art. $1^{\circ}$ ). Peso 1

Bloco 3.2 - Comitês - Peso 2

25. O Estatuto Social prevê Comitê de Elegibilidade Estatutário (Lei 13.303/16, art. 10 e 6 ${ }^{\circ}$; Decreto 32.243/17, art. $1^{\circ}$, caput, e $\S 2^{\circ}$ ). Peso 1

26. O Estatuto Social prevê Comitê de Auditoria Estatutário (Lei 13.303/16, art. $9^{\circ}$, III, $6^{\text {o }}$; Decreto 32.243/17, art. $1^{\circ}$, caput, e $\S 2^{\circ}$ ). Peso 1

Bloco 3.3 - Requisitos e Vedações - Peso 3

27. O Estatuto Social estabelece os requisitos e vedações para administradores (Lei 13.303/16, arts. $17,26,1^{\circ}, \S 1^{\circ}, 6^{\circ}$ e 16 ; Decretos $32.112 / 16$, art. $6^{\circ}$, e $32.243 / 17$, art. $1^{\circ}$, caput, e $\S 2^{\circ}$ ). Peso 5

28. O Estatuto Social estabelece os requisitos e vedações para conselheiros fiscais (Lei $13.303 / 16$, arts. $17,26,1^{\circ}, \S 1^{\circ}$, e $6^{\circ}$; Decretos 32.112/16, art. 10 e $\S$ único, e 32.243/17, art. $1^{\circ}$, caput, e $\left.\S 2^{\circ}\right)$. Peso 5

29. O Estatuto Social estabelece os requisitos específicos para exercício dos cargos de Diretores (Lei 13.303/16, art. 13, II; Decretos 32.112/16, art. $3^{\circ}$, II, e $32.243 / 17$, art. $1^{\circ}$, caput, e $\$ 2^{\circ}$ ). Peso 3 
30. O Estatuto Social estabelece os requisitos e vedações para a indicação dos membros do Conselho de Administração (Lei 13.303/16, arts. $1^{\circ}, \S 1^{\circ}, 16, \S$ único, $6^{\circ}, 17$ e 26 ; e Decretos $32.112 / 16$, art. $6^{\circ}$, e $32.243 / 17$, art. $1^{\circ}$, caput, e $\$ 2^{\circ}$ ). Peso 5

31. O Estatuto Social estabelece requisitos e vedações para os membros do Comitê de Auditoria (Lei 13.303/16, art. $6^{\circ}$ e 25; Decreto 32.243/17, art. $1^{\circ}$, caput, e $\S 2^{\circ}$ ). Peso 5

Bloco 3.4 - Membros Independentes - Peso 2

32. O Estatuto Social prevê formalmente a participação de membros independentes no Conselho de Administração (Lei 13.303/16, art. 22 e 6 ${ }^{\circ}$; Decreto 32.243/17, art. $1^{\text {o }}$, caput, e $\S 2^{\circ}$ ). Peso 3

33. O Estatuto Social prevê formalmente a participação de membros independentes no Comitê de Auditoria Estatutário (Lei 13.303/16, art. 25 e $6^{\circ}$; e Decreto 32.243/17, art. $1^{\circ}$, caput, e $\S 2^{\circ}$ ). Peso 1 